University of Nebraska - Lincoln

DigitalCommons@University of Nebraska - Lincoln

USDA National Wildlife Research Center - Staff Publications
U.S. Department of Agriculture: Animal and Plant Health Inspection Service

April 2007

\title{
Coyote Investigative Behavior Following Removal of Novel Stimuli
}

Daniel J. Heffernan

Colorado State University, Fort Collins

William F. Andelt

Colorado State University, Fort Collins

John A. Shivik

Utah State University, Logan, UT

Follow this and additional works at: https://digitalcommons.unl.edu/icwdm_usdanwrc

Part of the Environmental Sciences Commons

Heffernan, Daniel J.; Andelt, William F.; and Shivik, John A., "Coyote Investigative Behavior Following Removal of Novel Stimuli" (2007). USDA National Wildlife Research Center - Staff Publications. 650. https://digitalcommons.unl.edu/icwdm_usdanwrc/650

This Article is brought to you for free and open access by the U.S. Department of Agriculture: Animal and Plant Health Inspection Service at DigitalCommons@University of Nebraska - Lincoln. It has been accepted for inclusion in USDA National Wildlife Research Center - Staff Publications by an authorized administrator of DigitalCommons@University of Nebraska - Lincoln. 


\title{
Coyote Investigative Behavior Following Removal of Novel Stimuli
}

\author{
DANIEL J. HEFFERNAN, ${ }^{1}$ Department of Fish, Wildife, and Conservation Biology, Colorado State University, Fort Collins, CO 80523 , USA \\ WILLIAM F. ANDELT, ${ }^{2}$ Department of Fish, Wildlife, and Conservation Biology, Colorado State University, Fort Collins, CO 80523, USA \\ JOHN A. SHIVIK, United States Department of Agriculture, Wildlife Services, National Wildlife Research Center, Department of Wildland Resources, \\ Utah State University, Logan, UT 84322, USA
}

\begin{abstract}
Because coyotes (Canis latrans) show an aversion to novel objects, we examined the effects of the presence and removal of repellent and attractive stimuli on coyote behavior. We found a greater proportion of captive coyotes investigated 10-cm-tall cones $(0.95)$ compared to 90 -cm-tall cones $(0.68)$ and control sites $(0.81)$, and spent longer periods $(P<0.001$ in all instances $)$ investigating small cones $(\bar{x}=$ $465 \mathrm{sec})$, compared to large cones $(\bar{x}=212 \mathrm{sec})$ and control sites $(\bar{x}=45 \mathrm{sec})$. However, investigation times at sites following removal of large cones were 1.6 and 2.3 times greater than investigation times at sites following removal of small cones and the control, respectively. Results from pen studies were supported by a field study. Wild coyotes in south Texas visited $43 \%$ of small cones but did not visit large cones. Following removal of cones, visits to small cone stations decreased to $29 \%$, whereas coyotes visited $43 \%$ of large cone stations. Thus, we observed a direct relationship between aversion toward large novel objects and subsequent attraction to sites following their removal among both captive and wild coyotes. Based upon our results, we suggest that placing large novel objects over traps that are set and removing such objects after a few days, with the subsequent addition of an olfactory attractant, may increase exploratory behavior and capture of coyotes. (JOURNAL OF WILDLIFE MANAGEMENT 71(2):587-593; 2007)
\end{abstract}

DOI: $10.2193 / 2005-505$

KEY WORDS attractant, behavior, Canis latrans, coyote, novel stimuli, scent-station, vision.

Novel objects and novel prey evoke a conflict between curiosity and fear (Montgomery 1955, Curio 1976). Schneirla (1965) suggested that weaker stimuli, such as soft noises, regular and slow movement, and small size are more likely to elicit approach in neonate vertebrates, whereas stronger stimuli, such as loud noises, rapid and irregular movement, and large size elicit a withdrawal reaction. Ruggiero et al. (1979) reported American kestrels (Falco sparverius) selected nonmoving novel prey over moving novel prey, indicating the combination of movement and novel appearance was likely too strong a stimulus to elicit exploration. Windberg (1996) reported captive coyotes (Canis latrans) were more averse to large than to small novel objects.

Responses of coyotes to novel stimuli are important when designing and deploying attractants or capture and control devices. Previous research suggested that novel prey animals and electric models presented in cages frequently elicited neophobic or withdrawal responses from captive coyotes (Heffernan 2002). We conducted formal experiments on captive and free-ranging coyotes to assess coyote responses to the presence and removal of small and large novel objects. We hypothesized that, after removal of novel objects, coyotes would be more attracted to sites where large novel objects, compared to small novel objects, had been placed.

Phillips et al. (1990) and Windberg (1996) found no differences between genders when testing responses of individual coyotes to novel visual and olfactory stimuli. However, Kimball et al. (2000) tested male-female pairs of coyotes and found females were often first to approach and spent longer periods interacting with novel olfactory

\footnotetext{
1 Present address: 40 Millside Lane, Mill Valley, CA 94941, USA

2 E-mail: billan@warnercnr.colostate.edu
}

attractants, which suggests that the presence of a mate may influence individual coyote responses to novel stimuli, and hence, potentially influence response to the removal of a novel object. Because previous studies have not compared responses to novelty by solitary individuals and individuals in mated pairs, we also evaluated the effect of these variables on responses of coyotes to novel objects and their removal.

\section{STUDY AREA}

We conducted research on captive coyotes at the Wildlife Services, National Wildlife Research Center's Predator Research Facility, at Millville, Utah, USA. The 60-ha facility included 9 clover-pen complexes; each pen consisted of 3 fenced 0.1-ha enclosures radiating out from an observation building with one-way windows facing each pen. A concrete wall extended along the common sides of the 3 enclosures, partially obscuring the view between them.

We conducted field research 9-17 February 2001 on 3 private ranches near the Rob and Bessie Welder Wildlife Refuge (WWR) in south Texas, USA: the 22,257-ha Welder-McCann Ranch northwest of WWR, the 3,642-ha Pat Welder Ranch southwest of WWR, and the 6,070-ha David Edwards Ranch west of WWR. The WWR was located approximately $50 \mathrm{~km}$ north of Corpus Christi, Texas; for a detailed description of WWR see Andelt (1985). Coyote control on all 3 ranches was minimal (T. L. Blankenship, Rob and Bessie Welder Wildlife Foundation, personal communication).

\section{METHODS}

\section{Pen Studies}

We randomly selected and tested 12 male-female pairs of coyotes and 21 male and 21 female coyotes that were 
maintained alone. We tested the paired male and female coyotes together in clover pens where they had been living, whereas we moved the solitary coyotes from kennels, placed them in clover pens, and then tested them alone $>24$ hours later (Heffernan 2002).

We presented each solitary coyote and mated pair with 3 treatments, one at a time at random over 3 days of testing; treatments included the following: 1) a large, $90-\mathrm{cm}$-tall by 25-cm-diameter traffic cone (Radiator Specialty Company, Charlotte, NC), 2) a small, 10-cm-tall by 6.25 -cm-diameter traffic cone (Lakeside Plastics, Oshkosh, WI), and 3) a control (no cone). Large and small cones were polyurethane plastic, bright orange, and uniform in appearance and texture. We presented each of the 3 treatments to either 3 or 6 coyotes each day.

In pretrial screening of 3 coyotes (not included in this study), we restrained coyotes in the concrete den areas of the observation buildings prior to the presentation of treatments. This technique was stressful to individual animals before and after release into the outdoor pens, thus we subsequently presented treatments to individual coyotes already present in the outdoor testing area. For each trial, we placed a cloth sheet over cones before entering test pens to prevent coyotes in proximate pens from viewing treatments, and to obscure treatments from the test subject for as long as possible. We walked to a predetermined location within $3 \mathrm{~m}$ of the center of the pen, based on proximity to landmarks that could be easily identified on videotape, removed the sheet, and staked cones to the ground. We filled small cones with quick-dry cement to reduce damage by coyotes, and placed a 10-cm-tall cone-shaped piece of cement under the large cones to mimic potential effects of scent from the concrete present in the small cone. For the control, we carried a stake under the sheet into the pen, crouched down at a predetermined location, and pounded the stake with a mallet to mimic the activity of setting cones. We used different locations within pens for each trial.

Our pretrial screening indicated that coyotes sometimes waited $>15$ minutes before approaching within $1 \mathrm{~m}$ of treatments. Thus, while treatments were present, we recorded activity at the treatment site for 30 minutes using video cameras in the central observation building of testing pens. After 30 minutes we re-entered the pens and at control sites we pounded a stake into the ground and pulled it out to mimic the disturbance to substrate following removal of a cone. At sites containing cones, we removed stakes from the cone and pounded a stake several times with the mallet to mimic activity following removal of the control. We then placed a sheet over the stake or the stake and cone and removed them from the pen. We terminated video recordings 15 minutes after removal of treatments because pretrial screening indicated that coyotes that did not approach treatment sites within 15 minutes also did not approach treatment sites within 30 minutes.

We recorded the length of time in seconds (investigation time) coyotes spent $\leq 2 \mathrm{~m}$ from treatments and at those sites following removal of treatments. We recorded the presence and absence of the following behaviors: approaching within $2 \mathrm{~m}$, rub-rolling, scent-marking, digging, biting, and striking the cone with the front paws. Four solitary coyotes during 2000, and 7 solitary coyotes and 3 coyotes from 3 mated pairs during 2001, removed the small cone from the ground prior to the end of the trial. We excluded these coyotes from our analyses of small cone investigation times and responses to the removal of small cones.

We used logistic regression with a logit link and a binomial distribution (PROC GENMOD; SAS Version 9.1, SAS Institute, Cary, NC) to determine the effects of treatment, gender, and status (solitary vs. mated pair) on the proportion of coyotes investigating treatments and displaying various behaviors within $2 \mathrm{~m}$ of treatments and at sites following removal of treatments. We used a general linear model analysis of variance (PROC GLM) to determine the effects of treatment, gender, status, and interactions between treatment and gender and between treatment and status on investigation times at treatments and following removal of treatments. We used linear contrasts to compare means in PROC GENMOD and least squares means for multiple comparisons in PROC GLM. Finally, we used chi-square tables (PROC FREQ) to compare various behaviors between genders of coyotes and within mated pairs of coyotes. We used Fisher's Exact Test within PROC FREQ when individual cell sizes were small.

\section{Field Study}

We used modified scent stations consisting of 1 -m-diameter circles of sifted soil (Linhart and Knowlton 1975, Roughton and Sweeney 1982) to compare coyote visitation to 4 treatments: 1) fatty acid-scented (FAS) plaster disc, 2) small, $10-\mathrm{cm}$-tall by $6.25-\mathrm{cm}$-diameter orange plastic cone, 3) large, $90-\mathrm{cm}$-tall by $25-\mathrm{cm}$-diameter orange plastic cone, and 4) control station (no object). We set 112 stations in 28 groups of 4 stations; each station within a group consisted of a different treatment selected randomly after preparation of an untreated station. We set 7 groups of stations/day over 4 consecutive days. We randomly plotted groups on a map and set them $\geq 1.7 \mathrm{~km}$ apart. This ensured that $\leq 2$ groups of stations were within the home range of a resident group of coyotes, based on average home range sizes of $4.7 \mathrm{~km}^{2}$ and $4.3 \mathrm{~km}^{2}$ for resident adult males and females, respectively, in this area (Andelt 1985). We spaced stations at 100-m intervals within groups and approximately $1 \mathrm{~m}$ from alternate sides of unpaved roads (Heffernan 2002). We filled small cones with quick-dry cement, placed a $10-\mathrm{cm}-$ tall cone-shaped piece of cement under the large cones, and cross-staked small and large cones with $30-\mathrm{cm}$ steel stakes at the center of stations. We placed an attractant disk in the center of FAS stations; control stations were circles of sifted substrate.

We recorded coyote visits at stations for 2 consecutive mornings while treatments were present (preremoval period). We then removed cones from stations, but did not remove FAS, and checked stations for 2 more mornings (postremoval period). We combined observations over each 2-day period and considered each station as visited or not 
Table 1. Proportion of captive coyotes that exhibited various behaviors $\leq 2 \mathrm{~m}$ from small traffic cones, large traffic cones, and a control (no treatment), and investigated sites after removal of treatments at the National Wildlife Research Center's Predator Research Facility, Millville, Utah, USA, during November 2000 and July-August 2001.

\begin{tabular}{|c|c|c|c|c|c|c|c|c|c|}
\hline \multirow[b]{3}{*}{ Period $^{\mathrm{a}}$ and behavior } & \multicolumn{6}{|c|}{ Treatment } & \multirow[b]{3}{*}{ df } & \multirow[b]{3}{*}{$\chi^{2}$} & \multirow[b]{3}{*}{$P$} \\
\hline & \multicolumn{2}{|c|}{ Small cone } & \multicolumn{2}{|c|}{ Large cone } & \multicolumn{2}{|c|}{ Control } & & & \\
\hline & $n$ & $\bar{x}$ & $n$ & $\bar{x}$ & $n$ & $\bar{x}$ & & & \\
\hline \multicolumn{10}{|l|}{ Preremoval } \\
\hline Proportion investigating & 65 & $0.95 \mathrm{~A}^{\mathrm{b}}$ & 66 & $0.68 \mathrm{~B}$ & 64 & $0.81 \mathrm{~B}$ & 2,190 & 21.87 & $<0.001$ \\
\hline Rub-roll & 65 & $0.51 \mathrm{~A}$ & 66 & 0.09B & 64 & $0.00 \mathrm{C}$ & 2,190 & 95.36 & $<0.001$ \\
\hline Scent-mark & 65 & $0.43 \mathrm{~A}$ & 66 & $0.11 \mathrm{~B}$ & 64 & $0.23 \mathrm{C}$ & 2,190 & 20.81 & $<0.001$ \\
\hline Dig & 65 & $0.42 \mathrm{~A}$ & 66 & 0.09B & 64 & $0.03 \mathrm{~B}$ & 2,190 & 51.27 & $<0.001$ \\
\hline Bite-pull & 66 & $0.77 \mathrm{~A}$ & 66 & $0.11 \mathrm{~B}$ & 64 & $0.00 \mathrm{C}$ & 2,191 & 206.25 & $<0.001$ \\
\hline Strike with paw & 66 & $0.45 \mathrm{~A}$ & 66 & $0.08 \mathrm{~B}$ & 64 & $0.00 \mathrm{C}$ & 2,191 & 92.16 & $<0.001$ \\
\hline \multicolumn{10}{|l|}{ Postremoval } \\
\hline Proportion investigating & 48 & $0.96 \mathrm{~A}$ & 63 & $0.98 \mathrm{~A}$ & 62 & $0.74 \mathrm{~B}$ & 2,168 & 39.68 & $<0.001$ \\
\hline Rub-roll & 48 & $0.21 \mathrm{~A}$ & 63 & $0.16 \mathrm{~A}$ & 62 & $0.00 \mathrm{~B}$ & 2,168 & 32.91 & $<0.001$ \\
\hline Scent-mark & 48 & $0.69 \mathrm{~A}$ & 63 & $0.65 \mathrm{~A}$ & 62 & $0.24 \mathrm{~B}$ & 2,168 & 32.90 & $<0.001$ \\
\hline Dig & 48 & $0.27 \mathrm{~A}$ & 63 & $0.19 \mathrm{~A}$ & 62 & $0.13 \mathrm{~A}$ & 2,168 & 3.70 & 0.157 \\
\hline
\end{tabular}

${ }^{\mathrm{a}}$ We monitored coyotes for $1,800 \mathrm{sec}$ during preremoval and $900 \mathrm{sec}$ during postremoval trials.

${ }^{\mathrm{b}}$ Means with different letters in the same row are significantly different $(P<0.05)$.

visited during the 2-day preremoval and postremoval periods. If high winds, livestock, or rain heavily damaged a station, we considered that station inoperable for the previous night and reset the station.

We used PROC GENMOD to determine the effects of treatment, period, and a possible interaction between treatment and period on the proportion of stations visited by coyotes. We used linear contrasts to compare treatment means. This study was approved by Colorado State University's Institutional Animal Care and Use Committee (protocols 00-113A-01 and 01-134A-01) and by the United States Department of Agriculture, Wildlife Services, National Wildlife Research Center's Institutional Animal Care and Use Committee (protocol QA 818).

\section{RESULTS}

\section{Pen Studies: Investigation of Treatments}

Sixty-five of 66 captive coyotes investigated $\geq 1$ treatment. A greater proportion of coyotes investigated the small cone $(\bar{x}=0.95)$ compared to the large cone $(\bar{x}=0.68)$ and control $(\bar{x}=0.81$; Table 1$)$. A greater proportion of males $(\bar{x}=0.88)$ compared to females $(\bar{x}=0.76)$ investigated all treatments (Table 2). Specifically, a greater proportion $\left(\chi^{2}{ }_{1}=5.657, P=\right.$ $0.017)$ of males $(n=33, \bar{x}=0.82)$ than females $(n=33, \bar{x}=$ $0.55)$ investigated large cones, but similar proportions of males and females investigated the small cone $(P=1.000$, Fisher's Exact Test $)$ and the control $\left(\chi_{1}^{2}=1.641, P=\right.$ 0.200). Similar proportions of solitary compared to paired coyotes investigated all treatments combined (Table 3).

Coyotes spent a greater proportion of time within $2 \mathrm{~m}$ of small cones $(\bar{x}=0.26)$ compared to large cones $(\bar{x}=0.12)$ and the control $(\bar{x}=0.02)$ and more time within $2 \mathrm{~m}$ of large cones than the control $\left(F_{2,170}=33.83, P<0.001\right.$; Fig. 1$)$. Investigation times toward all treatments combined were similar between males and females (Table 2) and between solitary and paired coyotes (Table 3 ). Interactions between gender and treatment $\left(F_{2,170}=2.70, P=0.070\right)$ and between status and treatment $\left(F_{2,170}=2.65, P=0.073\right)$ were not significant, indicating males versus females and solitary versus paired coyotes spent similar durations investigating the various treatments.

Greater proportions of coyotes rub-rolled, scent-marked, and dug within $2 \mathrm{~m}$ of small cones $(\bar{x}=0.51,0.43,0.42$, respectively) compared to large cones $(\bar{x}=0.09,0.11,0.09$, respectively) and control sites $(\bar{x}=0.00,0.23,0.03$; Table 1$)$. Greater proportions of coyotes rub-rolled within $2 \mathrm{~m}$ of large cones compared to control sites, whereas greater proportions of coyotes scent-marked on control than on large-cone sites. Greater proportions of coyotes also bitepulled and struck, with their paws, small cones $(\bar{x}=0.77$ and 0.45 , respectively) compared to large cones $(\bar{x}=0.11$ and 0.08 , respectively) and control sites $(\bar{x}=0.00,0.00)$, and greater proportions of coyotes bite-pulled and struck the large cones compared to control sites. Similar proportions of males and females exhibited rub-roll, scent-marking, digging, bite-pull, and strike behaviors (Table 2). A greater proportion of solitary $(\bar{x}=0.22,0.22)$ compared to paired $(\bar{x}$ $=0.11,0.11)$ coyotes exhibited digging and striking behavior, whereas a greater proportion of paired $(\bar{x}=0.42)$ compared to solitary $(\bar{x}=0.16)$ coyotes scent-marked (Table 3). Similar proportions of solitary and paired coyotes exhibited rub-rolling and bite-pull behaviors.

Typical behavior exhibited toward the large cone included circling at $<2 \mathrm{~m}$ while staring at the cone or sniffing the air or ground nearby and repeatedly approaching $<2 \mathrm{~m}$ of the cone and immediately withdrawing $>2 \mathrm{~m}$ from the cone. Physical interactions with the large cone were infrequent (Table 1) and were always preceded by a slow, cautious approach. In contrast, coyotes quickly approached $<2 \mathrm{~m}$ of small cones and initiated biting and rub-rolling within several seconds of the beginning of the trial. Many coyotes spent the majority of their investigation time in direct contact with the small cone. Bite-pull behavior and rubrolling at the small cone was often intense, lasting for several 
Table 2. Effect of gender on proportion of captive coyotes that exhibited various behaviors $\leq 2 \mathrm{~m}$ from, and duration of time (sec) that coyotes investigated, 3 treatments combined (small traffic cones, large traffic cones, and a control [no treatment]), and investigation of these sites after removal of treatments at the National Wildlife Research Center's Predator Research Facility, Millville, Utah, USA during November 2000 and July-August 2001.

\begin{tabular}{|c|c|c|c|c|c|c|c|c|c|}
\hline \multirow[b]{3}{*}{ Period $^{\mathrm{a}}$ and behavior } & \multicolumn{6}{|c|}{ Gender } & \multirow[b]{3}{*}{ df } & \multirow[b]{3}{*}{$\chi^{2} / F$} & \multirow[b]{3}{*}{$P$} \\
\hline & \multicolumn{3}{|c|}{$\mathbf{M}$} & \multicolumn{3}{|c|}{$\mathbf{F}$} & & & \\
\hline & $n$ & $\bar{x}$ & SE & $n$ & $\bar{x}$ & SE & & & \\
\hline \multicolumn{10}{|l|}{ Preremoval } \\
\hline Proportion investigating & 97 & 0.88 & \multirow{7}{*}{36.2} & 98 & 0.76 & \multirow{7}{*}{31.3} & 1,190 & 6.41 & 0.011 \\
\hline Duration investigating $(\mathrm{sec})$ & 90 & 247.0 & & 89 & 195.1 & & 1,170 & 0.90 & 0.345 \\
\hline Rub-roll & 97 & 0.21 & & 98 & 0.19 & & 1,190 & 0.15 & 0.700 \\
\hline Scent-mark & 97 & 0.26 & & 98 & 0.26 & & 1,190 & 0.00 & 0.956 \\
\hline Dig & 97 & 0.19 & & 98 & 0.17 & & 1,190 & 0.14 & 0.713 \\
\hline Bite-pull & 98 & 0.32 & & 98 & 0.28 & & 1,191 & 1.51 & 0.219 \\
\hline Strike with paw & 98 & 0.18 & & 98 & 0.17 & & 1,191 & 0.08 & 0.779 \\
\hline \multicolumn{10}{|l|}{ Postremoval } \\
\hline Proportion investigating & 87 & 0.86 & \multirow{5}{*}{11.3} & 86 & 0.92 & \multirow{5}{*}{8.5} & 1,168 & 3.00 & 0.083 \\
\hline Duration investigating $(\mathrm{sec})$ & 87 & 93.6 & & 86 & 79.6 & & 1,164 & 1.23 & 0.268 \\
\hline Rub-roll & 87 & 0.14 & & 86 & 0.09 & & 1,168 & 1.53 & 0.216 \\
\hline Scent-mark & 87 & 0.44 & & 86 & 0.59 & & 1,168 & 5.26 & 0.022 \\
\hline Dig & 87 & 0.21 & & 86 & 0.17 & & 1,168 & 0.32 & 0.574 \\
\hline
\end{tabular}

${ }^{\mathrm{a}}$ We monitored coyotes for $1,800 \mathrm{sec}$ during preremoval and $900 \mathrm{sec}$ during postremoval trials.

minutes at a time and sometimes resulted in the coyote pulling the small cone from the ground. Parts of small cones were eaten as evidenced by presence of pieces of plastic in feces. Typical behavior toward the control was rapid approach and $\geq 1$ periods of sniffing on or $<1 \mathrm{~m}$ from the control location.

Within mated pairs, males approached treatments first in $51 \%$ of trials, whereas females approached first in $49 \%$ of trials. A greater proportion of paired males (11/12) than paired females $(6 / 12, P=0.069$, Fisher's Exact Test) investigated large cones, but males and females approached the small cone and control with similar frequency $(P=1.000$ in both cases, Fisher's Exact Test). We observed coyotes investigating treatments simultaneously for 7-60 seconds in $25 \%$ of trials; however, this did not occur during the initial investigation. Generally, one coyote of a mated pair investigated the treatment while the other coyote watched from a distance. The second coyote often began investigating after its mate had withdrawn from the treatment. Scentmarking by one coyote usually was followed by scentmarking at the same location by the other coyote.

\section{Pen Studies: Investigation Following Removal of Treatments}

All captive coyotes investigated $\geq 1$ treatment sites following removal of treatments. A greater proportion of coyotes investigated sites where we removed small cones $(\bar{x}=0.96)$ or large cones $(\bar{x}=0.98)$ compared to the control $(\bar{x}=0.74$; Table 1). Similar proportions of males and females (Table 2) and similar proportions of solitary and paired coyotes (Table

Table 3. Effect of status on proportion of captive coyotes that exhibited various behaviors $\leq 2 \mathrm{~m}$ from, and duration of time (sec) that coyotes investigated, 3 treatments combined (small traffic cones, large traffic cones, and a control [no treatment]), and investigation of these sites after removal of treatments at the National Wildlife Research Center's Predator Research Facility, Millville, Utah, USA, during November 2000 and July-August 2001.

\begin{tabular}{|c|c|c|c|c|c|c|c|c|c|}
\hline \multirow[b]{3}{*}{ Period $^{\mathrm{a}}$ and behavior } & \multicolumn{6}{|c|}{ Status } & \multirow[b]{3}{*}{ df } & \multirow[b]{3}{*}{$\chi^{2} / F$} & \multirow[b]{3}{*}{$P$} \\
\hline & \multicolumn{3}{|c|}{ Solitary } & \multicolumn{3}{|c|}{ Mated pair } & & & \\
\hline & $n$ & $\bar{x}$ & SE & $n$ & $\bar{x}$ & SE & & & \\
\hline \multicolumn{10}{|l|}{ Preremoval } \\
\hline Proportion investigating & 123 & 0.79 & & 72 & 0.86 & & 1,190 & 2.10 & 0.147 \\
\hline Duration investigating $(\mathrm{sec})$ & 112 & 232.0 & 32.4 & 67 & 203.2 & 34.3 & 1,170 & 0.28 & 0.601 \\
\hline Rub-roll & 123 & 0.19 & & 72 & 0.22 & & 1,190 & 0.77 & 0.381 \\
\hline Scent-mark & 123 & 0.16 & & 72 & 0.42 & & 1,190 & 16.91 & $<0.001$ \\
\hline Dig & 123 & 0.22 & & 72 & 0.11 & & 1,190 & 6.30 & 0.012 \\
\hline Bite-pull & 124 & 0.31 & & 72 & 0.28 & & 1,191 & 0.49 & 0.486 \\
\hline Strike with paw & 124 & 0.22 & & 72 & 0.11 & & 1,191 & 7.53 & 0.006 \\
\hline \multicolumn{10}{|l|}{ Postremoval } \\
\hline Proportion investigating & 109 & 0.88 & & 64 & 0.91 & & 1,168 & 0.87 & 0.350 \\
\hline Duration investigating (sec) & 109 & 92.1 & 10.1 & 64 & 77.3 & 8.4 & 1,164 & 0.60 & 0.440 \\
\hline Rub-roll & 109 & 0.15 & & 64 & 0.06 & & 1,168 & 5.04 & 0.025 \\
\hline Scent-mark & 109 & 0.40 & & 64 & 0.70 & & 1,168 & 18.49 & $<0.001$ \\
\hline Dig & 109 & 0.24 & & 64 & 0.11 & & 1,168 & 4.91 & 0.027 \\
\hline
\end{tabular}

${ }^{\mathrm{a}}$ We monitored coyotes for $1,800 \mathrm{sec}$ during preremoval and $900 \mathrm{sec}$ during postremoval trials. 


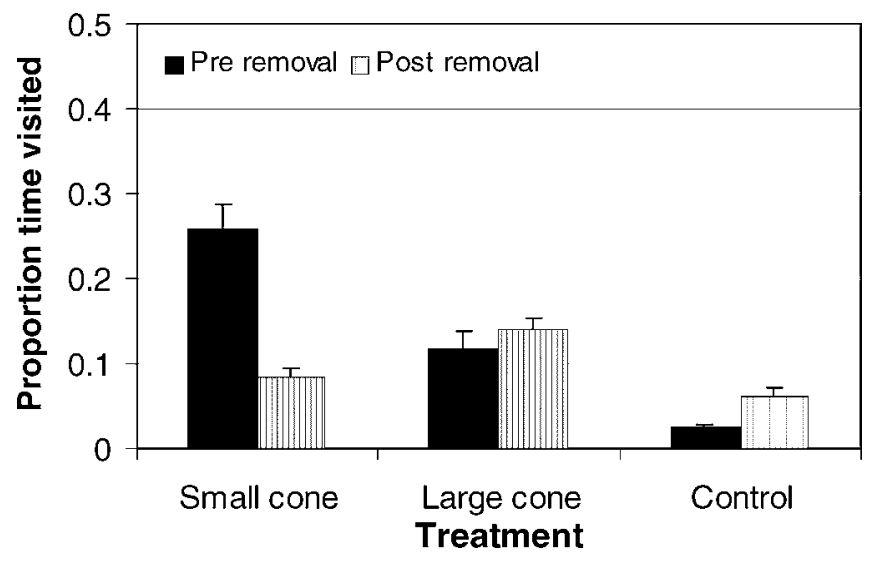

Figure 1. Effect of treatment (small cone, large cone, control,) and period (preremoval, postremoval) on proportion of time (preremoval $=30-\mathrm{min}$ period, $n=49-66 /$ treatment; postremoval $=15-\min$ period, $n=48-63 /$ treatment) that captive coyotes investigated sites at the National Wildlife Research Center's Predator Research Facility, Millville, Utah, USA, during November 2000 and July-August 2001. We present standard errors above each bar.

3) approached all treatment sites combined after removal of treatments.

Coyotes spent a greater proportion of time investigating large-cone sites $(\bar{x}=0.14)$ compared to small-cone $(\bar{x}=$ $0.09)$ and control sites $(\bar{x}=0.06)$ following removal of these treatments $\left(F_{2,164}=8.26, P<0.001 ;\right.$ Fig. 1). Investigation times at all sites combined following removal of treatments were similar between males and females (Table 2), and between solitary and paired coyotes (Table 3 ). Interactions between gender and treatment $\left(F_{2,164}=0.92, P=0.402\right)$ and between status and treatment $\left(F_{2,164}=1.10, P=0.336\right)$ were not significant, indicating males versus females and solitary versus paired coyotes responded similarly to removal of the various treatments.

Greater proportions of coyotes rub-rolled and scentmarked at small-cone $(\bar{x}=0.21,0.69)$ and large-cone $(\bar{x}=$ $0.16,0.65)$ sites compared to control $(\bar{x}=0.00,0.24)$ sites following removal of treatments (Table 1). Similar proportions of coyotes dug at each of the 3 treatment sites following removal of treatments (Table 1). A greater proportion of females $(\bar{x}=0.59)$ compared to males $(\bar{x}=$ $0.44)$ scent-marked at sites following removal of treatments, whereas similar proportions of males and females exhibited rub-rolling and digging following removal of treatments (Table 2). A greater proportion of solitary $(\bar{x}=0.15,0.24)$ compared to paired $(\bar{x}=0.06,0.11)$ coyotes rub-rolled and dug, whereas a greater proportion of paired $(\bar{x}=0.70)$ compared to solitary $(\bar{x}=0.40)$ coyotes scent-marked at sites following removal of treatments (Table 3 ).

Coyotes typically approached sites shortly after we removed treatments and often made multiple investigations of these sites. Typical behavior involved sniffing the ground rapidly for varying periods of time before scent-marking multiple times, often accompanied by rub-rolling or digging for periods of a few seconds to several minutes.

Within mated pairs, males $(n=9)$ approached sites first after removal of treatments in $57 \%$ of trials, whereas

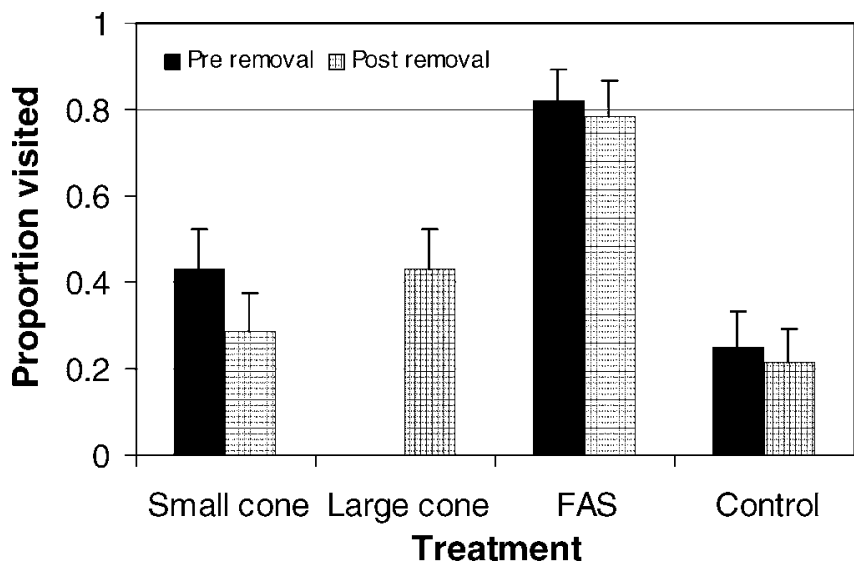

Figure 2. Effect of treatment (small cone, large cone, control, fatty acid scent $[\mathrm{FAS}]$ ) and period (preremoval, postremoval) on proportion of scent stations ( $n=28$ stations/treatment/period) visited by free-ranging coyotes on 3 ranches in south Texas, USA, from 9 February 2001 to 17 February 2001. Note: We recorded no visits at large cone stations during the preremoval period. We present standard errors above each bar.

females $(n=9)$ approached first in $43 \%$ of trials. All paired males and females investigated sites following removal of small and large cones. Further, similar proportions (Fisher's $P=1.000)$ of paired males $(\bar{x}=0.78)$ and females $(\bar{x}=0.89)$ investigated the control. Individuals in mated pairs generally took $\geq 1$ turn investigating sites following removal of treatments. We observed only 2 trials $(4 \%)$ in which coyotes investigated treatment sites simultaneously for short periods of time. Mated coyotes repeatedly scent-marked over each other's marks while investigating treatment sites.

\section{Field Study}

Coyotes visited a greater proportion $\left(\chi^{2}{ }_{1}=4.55, P=0.033\right)$ of 112 stations in the postremoval $(\bar{x}=0.43)$ compared to the preremoval period $(\bar{x}=0.38)$ of treatment objects. This higher overall visitation rate during postremoval was primarily influenced by visits to the large-cone sites (Fig. 2). During preremoval and postremoval periods combined, coyotes visited a greater proportion $\left(\chi_{3}^{2}=60.68, P<0.001\right)$ of FAS $(\bar{x}=0.80)$ than small-cone $(\bar{x}=0.36)$, large-cone $(\bar{x}$ $=0.21)$, and control $(\bar{x}=0.23)$ stations, but visitation rates did not vary among the other treatments. We found a strong interaction between treatment and period $\left(\chi^{2}{ }_{3}=19.63, P<\right.$ 0.001; Fig. 2); specifically, after we removed cones, the proportion of small-cone stations visited by coyotes decreased ( $\bar{x}=0.43$ vs. 0.29$)$, whereas the proportion of large-cone stations visited increased ( $\bar{x}=0.00$ vs. 0.43 ; Fig. 2).

We replaced damaged or missing FAS discs at 37 stations. Bite marks were visible on 4 small cones, and a small cone was removed from one station by a coyote.

\section{DISCUSSION}

Small cones were highly attractive to captive coyotes in our study. Rub-rolling against cones, bite-pulling of cones, and consumption of pieces of the cones likely was influenced by olfactory components of the small cone as well as the visual stimulus. In subsequent testing, captive coyotes were 
attracted to a synthetic lure, derived from 10 organic volatiles isolated from the plastic cones (R. Mauldin, National Wildlife Research Center, personal communication).

Captive male coyotes were more likely than female coyotes to approach within $2 \mathrm{~m}$ of large cones. Alpha male coyotes also generally lead attacks on large prey (Gese and Grothe 1995). Windberg (1996) found no qualitative difference between males and females in behavioral responses to novel objects that were considerably smaller than the large cone we used in this study. However, the general behavior of coyotes (circling and staring from a short distance, repeated approach-withdrawal movements) within $2 \mathrm{~m}$ of the large cone in our study corresponded to both Windberg's (1996) and Harris and Knowlton's (2001) descriptions of neophobic behavior towards novel objects.

The increased investigatory behavior elicited by removal of large cones compared to removal of small cones and controls that we observed among captive and free-ranging coyotes suggests a direct relationship between neophobia towards a novel object and attraction to a site following removal of the object. Animals engage in exploratory behavior to learn about their environment (Sheppe 1966). Coyotes likely can acquire information about an object, after it is removed, by investigating the site where the object had been. Coyotes that closely investigated or physically interacted with small cones may have less desire to acquire information following removal of small cones compared to following removal of large cones. Further, through repeated explorations, an animal becomes more familiar with their environment (Sheppe 1966). If intrusion of a novel object altered the coyotes' perception of familiarity with their environment, exploration following removal of novel objects might allow re-familiarization of the area.

Novel odors elicit both rub-rolling and scent-marking in carnivores (Kleiman 1966, Reiger 1979, Scrivner et al. 1987, Phillips et al. 1990, Kimball et al. 2000). The proportion of coyotes exhibiting rub-rolling and scent-marking following removal of treatments was similar between large and small cones. Thus, these behaviors likely are not related to the strength of a novel stimulus (i.e., size) but may be a response to the novelty of the stimulus itself. Rub-rolling and scentmarking behavior following removal of cones may be an attempt by coyotes to reduce novelty of the object's presence by mingling any lingering novel odor on the ground with the coyote's own scent (Kleiman 1966, Fox 1971). Some coyotes scent-marked at control sites, suggesting a response to our activity in the pen. Investigations accompanied by rub-rolling and scent-marking also may be another method for coyotes to reacquaint themselves with their territory following the temporary intrusion of the novel object or observer (Kleiman 1966, Bullard 1982). Alternatively, scentmarking following removal of treatments or observer activity may serve to reinforce territorial boundaries against future intrusions (Bowen and McTaggart-Cowan 1980, Bekoff and Wells 1986).

The increased scent-marking by paired compared to solitary coyotes in response to treatments and removal of treatments may have been related to social facilitation by mated coyotes. This increased behavior also may have been related to mated pairs being in pens for longer periods before exposure to treatments, and this increased familiarity with pens may have caused more territorial scent-marking. Whereas paired males were somewhat more likely to investigate large cones than their mates, this seemed to be the trend for males in general, and likely not a result of social facilitation.

In contrast to captive coyotes, wild coyotes in south Texas, USA, visited and bit a smaller proportion of small cones and did not visit large cones. This suggests that wild coyotes may be more cautious of novel objects than captive coyotes. This may be an artifact of captivity; captive animals likely have few negative experiences associated with novel objects and thus less incentive for caution (Harris and Knowlton 2001). Alternatively, lower levels of caution or more neophilic responses to novelty among captive coyotes may be associated with a relatively stimuli-impoverished captive environment (Stokes and Balph 1965).

Vision has been identified as a critical sensory modality in coyote predatory behavior (Wells 1978, Wells and Lehner 1978, Wells and Bekoff 1982). In our field study, FAS was considerably more attractive than small cones and removal of large cones. However, small visual attractants (Mason and Burns 1997) and removal of large visual attractants have potential to be attractive under variable environmental conditions such as temperature, winds, and moisture that can reduce the effectiveness of some olfactory attractants (Turkowski et al. 1979, 1983; Linhart 1981).

Predators rely on multiple sensory modalities and are most effective at hunting when both visual and olfactory stimuli are present (Curio 1976, Wells and Lehner 1978, Shivik 1998). We subsequently compared FAS, small cones, and both combined in the wild, but an absence of visits by coyotes did not allow any conclusions (Heffernan 2002).

\section{MANAGEMENT IMPLICATIONS}

The increased likelihood of coyotes investigating sites after placement and removal of large, compared to small, novel objects might be exploited to increase the success of capture devices. Traps could be set for a couple days under large novel objects in the field. Then the novel object might be removed, and an olfactory attractant could be added to the site to possibly increase exploratory behavior and capture of coyotes. Alternately, a small cone, similar to those used in this study, might be combined with an odor attractant to increase capture rates. Novel objects other than large cones may elicit a stronger neophobic response from coyotes, and subsequently, greater attraction to sites after their removal. Placement and removal of novel visual stimuli might also attract some animals that learned to avoid odor stimuli. Because alpha coyotes are more prone to approach and capture large prey (Gese and Grothe 1995, Sacks et al. 1999), but less prone to visit capture sites (Sequin et al. 2003), removing large novel stimuli might also be a method 
for targeting the capture of alpha coyotes. Our data suggest that biologists and managers should consider and research the interplay between visual, novel, and olfactory stimuli when attempting to attract more, or perhaps specific, animals to capture sites.

\section{ACKNOWLEDGMENTS}

We thank the United States Department of Agriculture, Wildlife Services, National Wildlife Research Center (NWRC) for funding this study. We appreciate the support of J. R. Mason, T. J. DeLiberto, A. Seglund, W. C. Pitt, F. F. Knowlton, D. E. Zemlicka, and others at the Millville Facility. We also greatly appreciate the advice and assistance of D. J. Martin and M. W. Fall at the NWRC. We thank D. L. Drawe and his staff at the Welder Wildlife Refuge for their assistance and hospitality. We also thank D. Edwards, B. Wyatt, and B. McCann for allowing access to their ranches and P. Guerrero, K. Fuerbacher, and E. Haner for assistance on the ranches. K. R. Wilson, D. J. Nash, K. P. Burnham, and R. M. Engeman provided research, statistical, and editorial suggestions.

\section{LITERATURE CITED}

Andelt, W. F. 1985. Behavioral ecology of coyotes in south Texas. Wildlife Monographs 94.

Bekoff, M., and M. C. Wells. 1986. Social ecology and behavior of coyotes. Advances in the Study of Behavior 16:251-338.

Bowen, W. D., and I. McTaggart-Cowan. 1980. Scent marking in coyotes. Canadian Journal of Zoology 58:473-480.

Bullard, R. W. 1982. Wild canid associations with fermentation products. Industrial and Engineering Chemistry Product Research and Development 21:646-655.

Curio, E. 1976. The ethology of predation. Springer-Verlag, Heidelberg, Germany.

Fox, M. W. 1971. Behaviour of wolves, dogs and related canids. Harper and Row, New York, New York, USA.

Gese, E. M., and S. Grothe. 1995. Analysis of coyote predation on deer and elk during winter in Yellowstone National Park, Wyoming. American Midland Naturalist 133:36-43.

Harris, C. E., and F. F. Knowlton. 2001. Differential responses of coyotes to novel stimuli in familiar and unfamiliar settings. Canadian Journal of Zoology 79:2005-2013.

Heffernan, D. J. 2002. Evaluation of multiple cues for increasing attraction of coyotes. Thesis, Colorado State University, Fort Collins, USA.

Kimball, B. A., J. R. Mason, F. S. Blom, J. J. Johnston, and D. E. Zemlicka. 2000. Development and testing of seven new synthetic coyote attractants. Journal of Agricultural and Food Chemistry 48:1892-1897.

Kleiman, D. 1966. Scent-marking in the Canidae. Symposia of the Zoological Society of London 18:167-177.

Linhart, S. B. 1981. Field evaluation of techniques for reducing coyote predation on livestock. Pages 1826-1838 in J. A. Chapman and D. Pursley, editors. Worldwide Furbearer Conference Proceedings. World- wide Furbearer Conference, Inc., 3-11 August 1980, Frostburg, Maryland, USA.

Linhart, S. B., and F. F. Knowlton. 1975. Determining the relative abundance of coyotes by scent station lines. Wildlife Society Bulletin 3: 119-124.

Mason, J. R., and R. J. Burns. 1997. Coyote responsiveness to novel visual stimuli. Journal of Wildlife Research 2:6-8.

Montgomery, K. C. 1955. The relation between fear induced by novel stimulation and exploratory behavior. Journal of Comparative and Physiological Psychology 48:254-260.

Phillips, R. L., F. S. Blom, and R. M. Engeman. 1990. Responses of captive coyotes to chemical attractants. Proceedings of the Vertebrate Pest Conference 14:285-290.

Reiger, I. 1979. Scent rubbing in carnivores. Carnivore 2:17-25.

Roughton, R. D., and M. W. Sweeney. 1982. Refinements in scent-station methodology for assessing trends in carnivore populations. Journal of Wildlife Management 46:217-229.

Ruggiero, L. F., C. D. Cheney, and F. F. Knowlton. 1979. Interacting prey characteristic effects on kestrel predatory behavior. American Naturalist 113:749-757.

Sacks, B. N., M. M. Jaeger, J. C. C. Neale, and D. R. McCullough. 1999. Territoriality and breeding status of coyotes relative to sheep predation. Journal of Wildlife Management 63:593-605.

Schneirla, T. C. 1965. Aspects of stimulation and organization in approach-withdrawal processes underlying vertebrate behavioral development. Advances in the Study of Behavior 1:1-74.

Scrivner, J. H., R. Teranishi, W. E. Howard, D. B. Fagre, and R. E. Marsh. 1987. Coyote attractants and a bait delivery system. Pages 38-55 in J. S. Green, editor. Protecting livestock from coyotes: a synopsis of the research of the Agricultural Research Service. U.S. Department of Agriculture Sheep Experiment Station, Dubois, Idaho, USA.

Sequin, E. S., M. M. Jaeger, P. F. Brussard, and R. H. Barrett. 2003. Wariness of coyotes to camera traps relative to social status and territory boundaries. Canadian Journal of Zoology 81:2015-2025.

Sheppe, W. 1966. Exploration by the deer mouse, Peromyscus leucopus. American Midland Naturalist 76:257-276.

Shivik, J. A. 1998. Brown tree snake response to visual and olfactory cues. Journal of Wildlife Management 62:105-111.

Stokes, A. W., and D. F. Balph. 1965. The relation of animal behavior to wildlife management. Transactions of the North American Wildlife and Natural Resources Conference 30:401-410.

Turkowski, F. J., M. L. Popelka, and R. W. Bullard. 1983. Efficacy of odor lures and baits for coyotes. Wildlife Society Bulletin 11:136-145.

Turkowski, F. J., M. L. Popelka, B. B. Green, and R. W. Bullard. 1979. Testing the responses of coyotes and other predators to odor attractants. Vertebrate Pest Control and Management Materials, American Society for Testing and Materials Special Publication 680:255-269.

Wells, M. C. 1978. Coyote senses in predation: environmental influences on their relative use. Behavioural Processes 3:149-158.

Wells, M. C., and M. Bekoff. 1982. Predation by wild coyotes: behavioral and ecological analyses. Journal of Mammalogy 63:118-127.

Wells, M. C., and P. N. Lehner. 1978. The relative importance of the distance senses in coyote predatory behaviour. Animal Behavior 26:251258.

Windberg, L. A. 1996. Coyote responses to visual and olfactory stimuli related to familiarity with an area. Canadian Journal of Zoology 74:22482253.

Associate Editor: Smallwood. 